Par son mésothorax concolore se rapproche de $C$. coelestina $\mathrm{Haag}$, mais son avant-corps est plus brillant et moins densément ponctué, surtout le prothorax.

Lytta bimaculatithorax, n. sp. - Angustata, nitida, modice pubescens, nigra, elytris nigro-cyaneis, thorace elongato, nigro, antice posticeque maculis testaceis notato.

Étroit et allongé, médiocrement pubescent, la pubescence grise plus distincte sur le dessous du corps, noir brillant, dessous parfois à reflets métalliques, élytres d'un noir bleuàtre moins brillants et ruguleusement ponctués, prothorax noir orné de deux macules testacées, une antérieure, l'autre basale. Tête presque carrée postérieurement, pubescente à l'état frais, assez grosse, bien plus large que le prothorax, à ponctuation moyenne, écartée, marquée d'une petite macule rousse frontale : antennes noires, grêles, filiformes, en partie longuement ciliées chez le $\sigma^{x}, 2^{e}$ article court, $3^{\text {e }}$ un peu plus long et plus large, moins épais $q, 4^{\mathrm{e}}$ et suivants longs; prothorax étroit et long, très rétréci en avant, marqué parfois d'un faible sillon médian, impressionné en arrière avec quelques points forts et écartés au milieu; élytres nettement plus larges que le prothorax, assez longs, subparallèles, à ponctuation dense, ruguleuse; pattes grêles, noires avec la base du $\mathbb{1}^{\mathrm{er}}$ article des tarses postérieurs testacée, $\mathbb{1}^{\mathrm{er}}$ article des tarses antérieurs chez $\sigma^{x}$ long et peu élargi, plus long ou moins épais chez $\subsetneq$. - Long. 16 - 20 mill.

Afrique orientale : Djibouti (coll. PIC).

Voisin de $L$. chalybea Er. dont il diffère par la forme de la tête, le prothorax presque lisse et bimaculé de testacé, enfin le $3^{\text {e }}$ article des antennes moins long.

\title{
Un nouvel Oligomyrmex de Cochinchine [Hym. Formicidae]
}

par le $D^{r}$ F. SAntschi.

Oligomyrmex Bouvardi, n. sp. - क . Long. 1,6 - 1,7 mill.. Jaune, gastre plus pâle; pubescence de poils dressés rares. Luisant, lisse, sauf quelques faibles rides sur les côtés du thorax et autour des

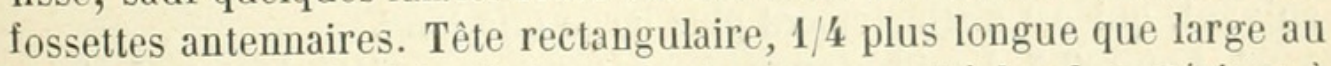
liers postérieur, à côtés distinctement convexes et à bord postérieur à 
peine concave. Yeux d'une facette, placés un peu en arrière du quart antérieur des côtés. Mandibules lisses, de כ̆ dents, les deux antérieures plus aiguës. L'épistome a deux carènes mousses un peu écartées en

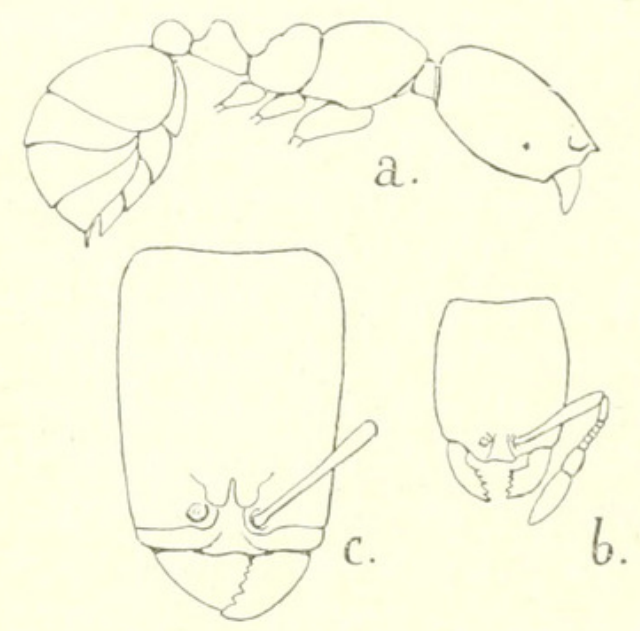

Fig. 1. - Oligomyrmex Bouvardi S ant schi. a, b, ouvrière. - c, tête du soldat. avant; le bord antérieur s'avance assez fortement dans son tiers médian où il est très légèrement échancré. Le scape dépasse un peu le quart postérieur de la tête. Articles 2 et 6 du funicule bien plus larges que longs. Pas de sutures promésonotales. Sillon mésoépinotal profond. Face basale de l'épinotum convexe, assez arrondie en avant, non bordée, aussi longue que la face déclive; celle-ci nettement bordée. 2 article du pédicule à peine plus large que le premier et aussi large derrière que devant.

2. Long. 2,4 mill. - Jaune; tête d'un jaune plus brunâtre, bord des mandibules et de l'épistome bruns. Gastre et membres jaune clair. Pubescence assez redressée, mélangée de poils plus longs, le tout assez abondant. Luisant, lisse avec quelques stries sur les joues et les lobes frontaux, et les côtés du métathorax finement réticulés. Tète rectangulaire d'un tiers plus longue que large, un peu rétrécie en avant, avec les côtés presque droits, et le bord postérieur légèrement concave. Yeux situés en avant du tiers antérieur, d'une ou deux facettes. Épistome bicaréné, aire frontale allongée, impressionnée. Mandibules lisses, de $\check{\partial}$ dents, les deux premières assez mousses. Le scape atteint presque

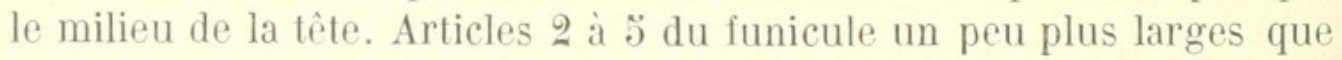
longs, le $6^{\text {e }}$ aussi long qu'épais et le dernier aussi long que les 4 précédents réunis. Côtés du pronotum fortement arrondis, suture promésonotale obsolète. Pronotum assez forment convexe sur le profil, le mésonotum l'est faiblement, avec une légère concavité entre les deux. Suture mésoépinotale profonde. Face basale de l'épinotum presque droite, un peu plus longue que large et aussi longue que la face déclive, laquelle est distinctement bordée et formant avec elle un angle de $140^{\circ}$. Premier nœud triangulaire, arrondi au sommet, presque perpendiculaire en arrière et très oblique en avant, aussi large que le suivant, qui est distinctement plus large que long.

๙. Long. 3,7-4 mill. Jaune brunâtre terne. Tête brune. Luisant 
et lisse. Tête mate et rugueuse, sauf un espace triangulaire très lisse et luisant en avant de l'ocelle médian. Tête trapézoïdale (y compris les yeux qui occupent presque les 23 antérieurs des côtés); l'épistome a une forte saillie longitudinale médiane, due à deux carènes assez écartées et dont l'intervalle est comblé. Nandibules de כ̌ dents, l'apicale 4 fois plus longue que les suivantes qui sont subégales. Scape à peine plus long que le $2^{e}$ article du funicule. Épinotum arrondi, sans tubercule. Premier article du pédicule d'un tiers plus long que haut, aminci et mousse au sommet; $2^{\mathrm{e}}$ article deux fois plus large que long. Ailes hyalines à nervures pâles, longues de 3,7 mill.

Cochinchine : Mitho, $\Varangle, \nsucc, \sigma^{\Upsilon}$ (Bouvard) et Saïgon, $\sigma^{x}$ (Ct Fouquet).

\section{Clé dichotomique des Oligomyrmex africains [Hym. Formicidae]}

par le $D^{\mathrm{r}}$ F. SAntschi.

A. - Ouvrières.

1. Deuxième article du pédicule plus long que large......

- Deuxième article du pédicule plus large que long.....

2. Tête $\mathbf{1 / 4}$ plus longue que large, ponctuée, thorax et pédicule allongés, épinotum inerme. Long. 1,2 mill.

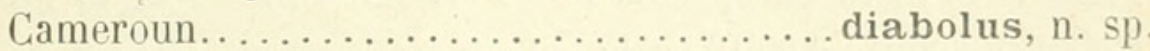

- Tête aussi large que longue, ridée ponctuée, thorax court, épinotum denté. Long. 0,8 mill. Kilimand-

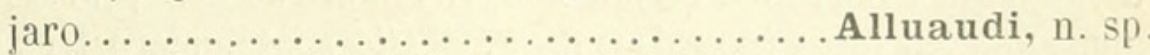

3. Longueur de 1,9 mill., les deux nœuds du pédicule

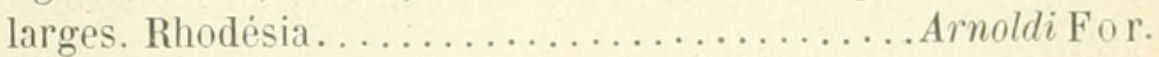

- Taille de moins d'un millimètre ................

4. Tête mate, densément ponctuée, $1^{\mathrm{er}}$ nœud du pédicule presque aussi large que le 2 e. Long. 0,8 mill. Guinée francaise ..........................

- Tête luisante, faiblement ponctuée, lisse. $1^{\mathrm{er}}$ article du pédicule notablement plus étroit que le 2 e........

๖. Suture métanotale à peine imprimée, face basale de l'épinotum courte. Long. 0,9 mill. Afr. orient. an-

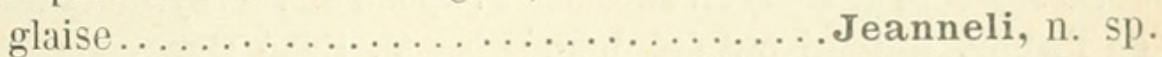

- Suture métanotale assez profonde, face basale plus longue. Long. 0,8 mill. Guinée française...... debilis, n. sp. 


\section{$2 \mathrm{BHL}$ Biodiversity Heritage Library}

1914. "Un nouvel Oligomyrmex da Cochinchine." Bulletin de la Société entomologique de France 1913, 457-459.

https://doi.org/10.5962/bhl.part.16312.

View This Item Online: https://www.biodiversitylibrary.org/item/36377

DOI: https://doi.org/10.5962/bhl.part.16312

Permalink: https://www.biodiversitylibrary.org/partpdf/16312

\section{Holding Institution}

Smithsonian Libraries

\section{Sponsored by}

Smithsonian

\section{Copyright \& Reuse}

Copyright Status: NOT_IN_COPYRIGHT

This document was created from content at the Biodiversity Heritage Library, the world's largest open access digital library for biodiversity literature and archives. Visit BHL at https://www.biodiversitylibrary.org. 